\title{
Effect of full-size and down-scaled accelerated traffic loading on pavement behavior
}

\author{
Martin Arraigada • Andrés Pugliessi • \\ Manfred N. Partl · Fernando Martinez
}

Received: 29 October 2013/Accepted: 23 April 2014/Published online: 6 May 2014

(C) RILEM 2014

\begin{abstract}
Accelerated pavement testing (APT) is an effective testing procedure to evaluate asphalt pavements. With APT it is possible to determine and measure the structural response and pavement performance under a controlled, accelerated damage accumulation in a compressed period of time. However, different types of APT technologies can lead to different results. Full-size loading devices simulate road traffic accurately, but are expensive, while down-scaled size simulators are cost effective, nevertheless further away from reality. In this work, two types of APT mobile load simulators with different loading characteristics are compared with respect to pavement response in the field and in the laboratory. The MLS10 is a full-size simulator, whereas the MMLS3 is a one-third scale device. The relationship between the devices was studied in terms of the measured strains induced by
\end{abstract}

M. Arraigada $(\bowtie) \cdot$ M. N. Partl

Road Engineering/Sealing Components Laboratory,

EMPA Duebendorf, Ueberlandstrasse 129, 8600

Duebendorf, Switzerland

e-mail: martin.arraigada@empa.ch

M. N. Partl

e-mail: manfred.partl@empa.ch

A. Pugliessi · F. Martinez

School of Engineering, National University of Rosario,

Berutti y Riobamba, 2000 Rosario, Argentina

e-mail: a.pugliessi@ityac.com.ar

F. Martinez

e-mail: femar@fceia.unr.edu.ar both machines in the same pavement. Therefore, a testing field was instrumented with strain gauges and first trafficked with MLS10. Later, a slab of the instrumented pavement was cut off the road and tested in the laboratory with the smaller MMLS3. Furthermore, the structure of the pavement was modelled with a viscoelastic finite element method model and the moving loads of both machines were simulated considering size, speed and approximate footprints of their tires. As for the pavement materials, the properties of the different asphalt layers were determined in the laboratory. Experimentally acquired strain data were used to validate the models. Stress fields under different loading and environmental conditions were analysed and compared. The evaluation shows that the models can predict the pavement response under different loading conditions. However, they still need to be improved to increase the accuracy under different conditions. Further, the analysis of the strains show that both load simulators induce a different stress-strain situation and scaling of the pavement should be considered.

Keywords Accelerated pavement testing . Pavement response $\cdot$ Pavement modelling

\section{Introduction}

The effect of traffic loading on the structural behaviour of a pavement depends on a wide number of variables such as size, distribution and sequence of the loads, 
vehicle speed and suspension, or the influence of the climate on the performance of the materials. For instance, it is well known $[1,2]$ that the gross weight of vehicles and it distribution among the axles has a dramatic influence on pavement durability. For pavement design, the characteristics of the loads are an even more decisive factor than the mere number of load repetitions. Hence, the impact of the loads on the pavement's strain-stress distribution requires careful study and analysis.

Pavement design guidelines worldwide are based and rely on the results from accelerated pavement testing (APT) studies. According to [3], APT means the controlled application of wheel loading to a layered pavement structure, to determine the response and performance under accumulation of damage in a compressed time period. This definition implies that APT requires rolling wheel loadings of a pavement, which could be a real construction or a pavement section specially built for testing purposes. Simulation of traffic can be done with real trucks on special testing fields or by machines that apply moving tire loads to the surface of an actual piece of road. Each APT method will load the pavement in a different way and will influence the performance of the structure accordingly, making the comparison between different APT results a non-trivial task. For example, [4] compared the rutting performance of the down-scaled (MMLS3) and full-size (WesTrack trucks) loading. It was found, that, in order to successfully compare both loading categories, several factor like tire contact stresses at elevated temperatures among others, have to be taken into account. Walubita et al. [5] presents a comparison of a performance test of a rehabilitated pavement, loaded with the full-size Texas mobile load simulator APT machine and the MMLS3. A good correlation of the induced deformation of the surface layers by both machines was recognized. In a more recent work, [6] the MMLS3 was used to scope research and provide guidelines for the selection and construction of full-size sections for MLS10 testing, showing the importance of scaling the pavement for the different types of load, as previously proposed by [7]. Other works [8, 9] or [10] address the importance of APT and modelling to evaluate the effect of different tires on the pavement behavior and damage.

This work presents experimental results evaluated in terms of strains obtained from a test on the same pavement by using two APT devices with loads of different scale. The first device, the mobile simulator MLS10, is a full-scale simulator and was applied in situ, whereas the second device, the model mobile load simulator MMLS3, is a so called third-scale load simulator and was used in the laboratory. Both devices differ essentially in size, amplitude and speed of the loading. The effect of the loading scale was assessed with strain gauges. Because of the different load configurations of the full-scale MLS10 and the downscaled MMLS3, the strain conditions induced in the same pavement are supposed to be different, possibly leading to different distress mechanisms. Therefore, this investigation focuses on correlating the strain response to the loading with both simulators including finite element model (FEM) analysis for both APT cases.

\section{Methodology}

APT facilities allow direct comparison of the effect of well-defined loads of different magnitudes, loading speeds, frequency, etc. The effect of different wheel load types on a pavement can be studied from the point of view of its long-term performance and short-term mechanical response. Long term pavement performance is related to the change of the materials characteristics as a result of repeated loadings and environmental influence. Short-term pavement response is related to the effect of a single axle or wheel pass and has to do with the immediate deformation of the layered system under loading. To investigate the influence of the loads on long term pavement performance, usually a large amount of repetitions is needed to cause permanent changes in the properties of a pavement, because deterioration is usually caused by material fatigue or accumulation of small permanent deformations. This means that evaluating pavement performance can be highly time consuming. As for short-term pavement response, stresses, strains and deflections are the physical values to be measured or calculated by analytical or numerical models.

\subsection{The mobile load simulator MSL10}

The MLS10 is a full-size mobile APT device with pneumatic tires and load magnitudes of the same size than of real traffic [11]. The machine loads the 
Fig. $13 \mathrm{D}$ view of the MLS10 frame and schema of the loading principle

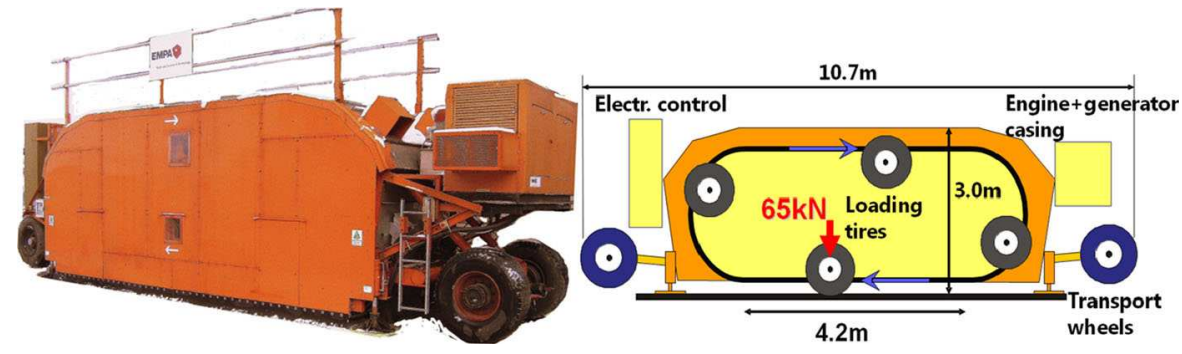

pavement with unidirectional tire passings over a length of about $4.2 \mathrm{~m}$, simulating half of an axle of a truck. The rolling speed of the tires can go upto $22 \mathrm{~km} /$ $\mathrm{h}$, reproducing the application of upto 6,000 half axles per hour, corresponding to a $1.6 \mathrm{~Hz}$ loading frequency. A hydro-pneumatic suspension system allows setting the loads applied by the tires upto $65 \mathrm{kN}$, corresponding to a $130 \mathrm{kN}$ axle load. The MLS10 can be equipped with single and twin tires. The machine has a total weight of $32 \mathrm{t}$ and is about $2.9 \mathrm{~m}$ wide, $3 \mathrm{~m}$ high and $10.7 \mathrm{~m}$ long. It consists of a steel frame made of two large iron plates connected through four robust tanks, attributing a very stiff configuration to the whole system. One of the tanks is used for water storage and the other three for diesel fuel, each having 1,3001 capacity. Attached to the internal face of the frame plates are two pairs of guide rails that form a closed loop path, like a chain saw.

The tires for loading the pavement are mounted in bogies, which are strong steel framed carriages that are coupled to a kind of chain rolling along the guide rails. The 4 bogies of the MLS10 have steel wheels that fit within the rails. The bogies are pulled contactless by 24 linear induction motors. The rails are built in such a way that the freely revolving tires touch down smoothly to the surface before loading the pavement over the trafficked path length. The distance between two consecutive tires is about $4.2 \mathrm{~m}$, meaning that only one tire is touching the pavement at a time. A schema of the loading system is depicted in Fig. 1.

\subsection{The model mobile load simulator MMLS3}

The MMLS3 is an APT device that applies a downscaled load with four single pneumatic tires [12]. They are smaller than standard truck tires, having a diameter of $0.3 \mathrm{~m}$ and a width of $0.11 \mathrm{~m}$. The machine is $2.4 \mathrm{~m}$ long by $0.6 \mathrm{~m}$ wide and $1.2 \mathrm{~m}$ high. Each tire loads the pavement width upto $2.1 \mathrm{kN}$ through a spring suspension system. At a maximum speed of $9 \mathrm{~km} / \mathrm{h}$, the MMLS3 allows approximately 7,200 load applications per hour, corresponding to approximately a $2 \mathrm{~Hz}$ loading frequency. The distance between two subsequent tires is $1.05 \mathrm{~m}$. In this case, the path length is $1 \mathrm{~m}$. The function principle is similar to the MLS10. A view and schema of the equipment is presented in Fig. 2.

\section{Experimental setup}

\subsection{Pavement structure and instrumentation}

In the first phase of this study, an experimental pavement section was built for APT long-term performance testing. Figure 3 presents a view of the structure, which was designed as a heavy duty fulldepth asphalt pavement corresponding to the thickest structural category as described in the dimensioning catalogue in the Swiss Standards [13]. It consisted of $3 \mathrm{~cm}$ wearing course of so-called macro-rough asphalt concrete AC MR 8 with an aggregate with a maximum nominal size of $8 \mathrm{~mm}$ and $6 \%$ modified binder PmB-E 45/80-65 CH. The bearing course comprised $8 \mathrm{~cm}$ of AC B $22 \mathrm{H}$ asphalt concrete with a maximum nominal size of $22 \mathrm{~mm}$ and $4.6 \%$ modified binder PmB-E 10/30-70. The base course was a $8 \mathrm{~cm}$ AC T 22H asphalt concrete with $22 \mathrm{~mm}$ maximum nominal size and $4.7 \%$ modified binder PmB-E 10/ 30-70. The asphalt layers were placed on top of a Stress Absorbing Membrane Interlayer (SAMI) that separate them from the two cement stabilized layers of 18 and $22 \mathrm{~cm}$ (Stabi. 1 and Stabi. 2).

The structure was instrumented with horizontal strain gauges and temperature sensors. The strain gauges (BL4, BQ4, TL4 and TQ4) were embedded 3 and $9 \mathrm{~cm}$ below the surface, in the interlayers of the asphalt concrete courses. They were positioned 
Fig. 2 View and schema of the MMLS3

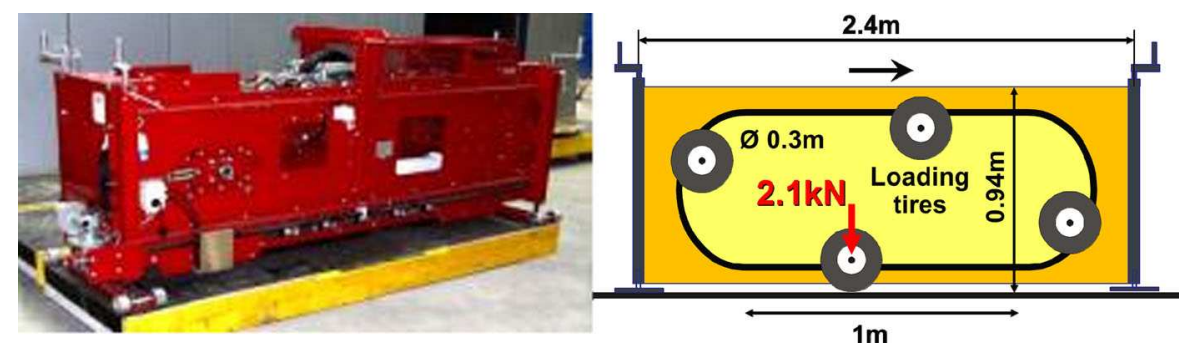

Fig. 3 Layout and instrumentation of the pavement, showing the labeling of the sensors

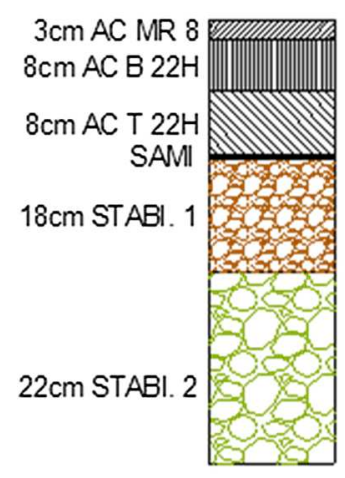

following a line coincident with the axis of trafficking, in a way that would fit in the gap within the twin tires of the MLS10. Each sensor was alternatively set perpendicular and longitudinal to the trafficking direction. Three temperature sensors (Th1 to Th3) were installed at the same depths and additionally one was placed on the pavement surface. The exact position of each measuring device installed in the pavement, is defined in Table 1.

\subsection{Test procedure}

During several months, the MLS10 was used to load the experimental pavement with tire passings of $65 \mathrm{kN}$ and a rolling speed of $22 \mathrm{~km} / \mathrm{h}$. This load corresponds to a truck axle of $130 \mathrm{kN}$. The load simulator was equipped with Goodyear 455/50 R22.5 twin tires and the inflation pressure was set with $0.75 \mathrm{MPa}$. No temperature control was used during trafficking. Strains and temperatures were collected during the course of the experiment. After completing the long-term performance tests, an asphalt slab of approximately $70 \mathrm{~cm}$ wide and $110 \mathrm{~cm}$ long was cut from the full-depth asphalt pavement (Fig. 4) and

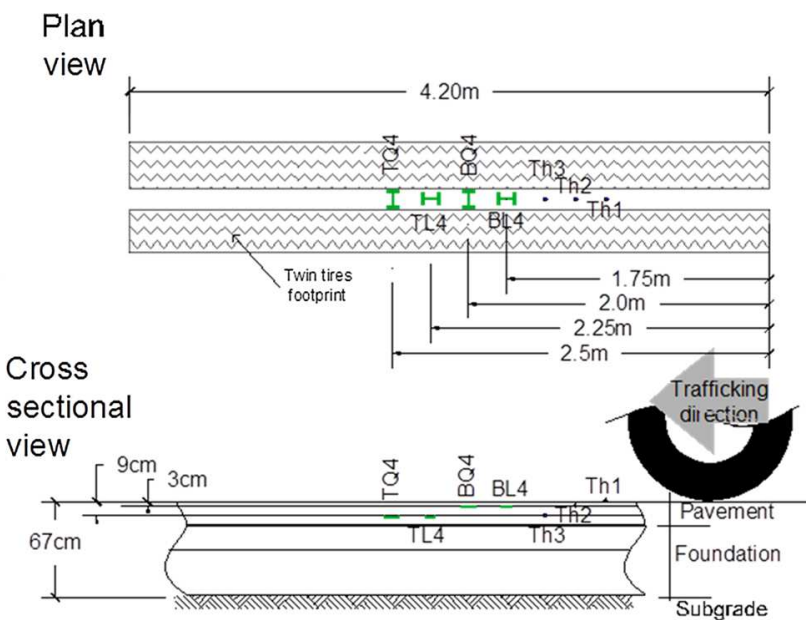

Table 1 Sensors position (arrows represent the trafficking direction)

\begin{tabular}{lllll}
\hline $\begin{array}{l}\text { Temperature } \\
\text { sensor }\end{array}$ & $\begin{array}{l}\text { Depth } \\
(\mathrm{cm})\end{array}$ & $\begin{array}{l}\text { Stain } \\
\text { gauge }\end{array}$ & $\begin{array}{l}\text { Depth } \\
(\mathrm{cm})\end{array}$ & Direction \\
\hline Th1 & 0 & BQ4 & -3 & \\
Th2 & -3 & BL4 & -3 & $\uparrow$ \\
Th3 & -11 & TQ4 & -11 & $\uparrow$ \\
& - & TL4 & -11 & $\uparrow$ \\
\hline
\end{tabular}

transported to the laboratory. This slab, already preloaded with 740,000 MLS10 load applications, contained all the embedded temperature sensors and strain gauges. The rest of the pavement was cored for laboratory testing.

Once in the laboratory, the slab was prepared for down-scaled trafficking with the MMLS3. All sensors 


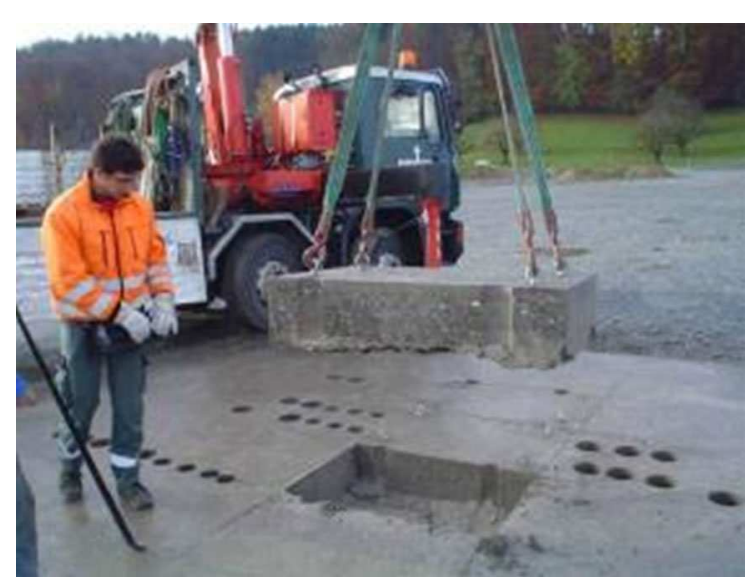

Fig. 4 Taking of the slab from the experimental pavement after MLS10 testing and coring

were re-connected to the data acquisition system (Fig. 5). A thin layer of cement/sand mix was spread between the slab and an underlying concrete block in order to provide stiff support. Everything was moved into a container with temperature control features. The MMLS3 was positioned on top of the slab in such a way, that the strain gauges embedded in the pavement were located directly under the rolling tires.

Previous to trafficking with the MMLS3, thermal conditioning of the slab was carried out for $24 \mathrm{~h}$ and at temperatures of $20,25,30$ and $35^{\circ} \mathrm{C}$. After reaching each of the temperatures, the MMLS3 was operated at different speeds $(1.5,3.4,5.3,7.1$ and $9.0 \mathrm{~km} / \mathrm{h})$. For each temperature-speed condition, measurements of strains and temperatures were carried out. The tires of the machine were inflated with 0.6 MPa.

In Table 2 there is a comparison of the characteristics of both, field and laboratory experimental settings.

\subsection{Strain analysis method}

In the experimental phase, a special methodology was used for data collection and evaluation. Since the amount of strain data to be collected is enormous, only a selection of the registered strains was saved. To that end, the data acquisition system was programmed to store strain data in blocks of $30 \mathrm{~s}$, leaving $5 \mathrm{~min}$ between each record. Strain data was saved as ASCII files and identified with the measurement time stamp. The sampling rate was set to 1,200 Hz. Measurements were triggered and recorded automatically.

Figure 6 shows a typical strain signal recorded with one of the gauges. In this example, only $2 \mathrm{~s}$ of the signal are displayed, showing the strains induced by the passing of three loading axles of the MLS10. The figure contains also the time stamp of the file as well as the measured temperatures. Temperatures were recorded using a separate data acquisition system and storing one value every $5 \mathrm{~min}$.

Positive values represent tensile and negative values compressive strains. However, due to normal baseline signal drift of the sensor as well as drift in the data acquisition system, or because of non-compensated temperature fluctuation, it is difficult to determine the zero-line. Consequently, all measurements were set to zero before start of recording.

Measurements were analysed automatically with a post processing script that works with the files the containing strains and the temperature measurements. This processing script performs the following steps:

- Low pass filtering of the records with $20 \mathrm{~Hz}$ cutoff frequency to clean for high frequency noise.
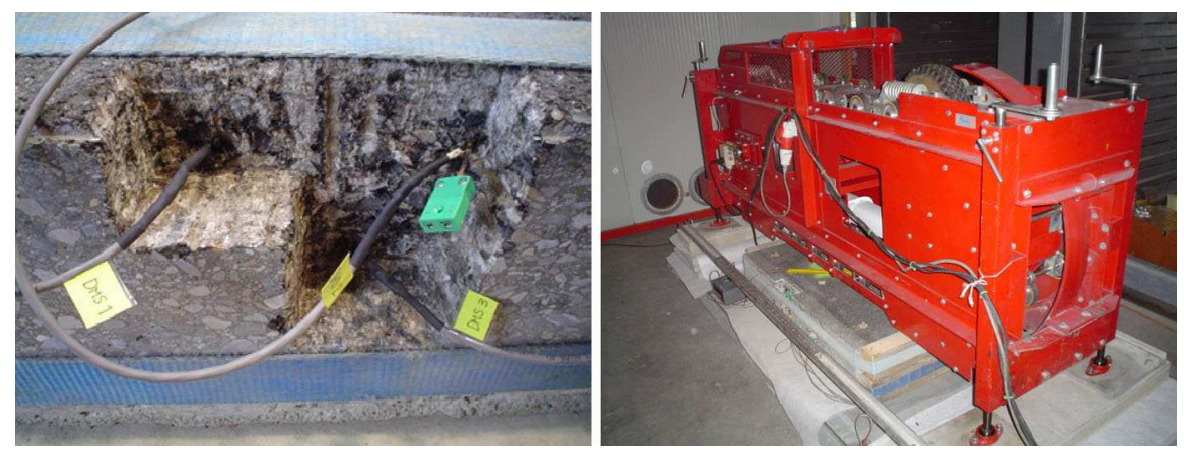

Fig. 5 Reconnection of the strain gauge cables and view of the setup 
Table 2 Summary of the testing conditions

\begin{tabular}{lll}
\hline & MLS10 & MMLS3 \\
\hline Pavement & Field test & Lab test \\
Load $(\mathrm{kN})$ & 65 & 2.1 \\
Load type & Twin tires & Single tire \\
& diameter $=0.54 \mathrm{~m}$ & diameter $=0.3 \mathrm{~m}$ \\
& width $=0.61 \mathrm{~m}$ & width $=0.11 \mathrm{~m}$ \\
Inflation pressure & 0.75 & 0.6 \\
$\quad$ MPa $)$ & & \\
$\begin{array}{l}\text { Speed }(\mathrm{km} / \mathrm{h}) \\
\text { Temperature }\left({ }^{\circ} \mathrm{C}\right)\end{array}$ & $\begin{array}{l}\text { Variable }(\mathrm{not} \\
\text { controlled })\end{array}$ & $20 ; 25 ; 30 ; 35$ \\
\hline
\end{tabular}

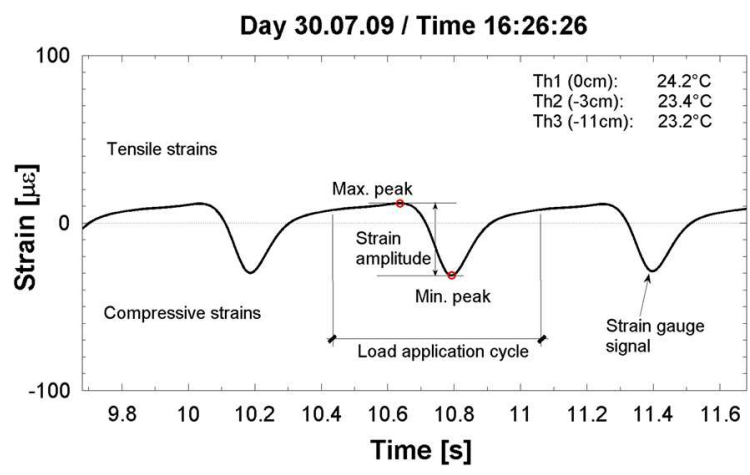

Fig. 6 Example of the strains recorded in the pavement by a strain gauge perpendicular to trafficking direction

- Calculation of the absolute difference between the maximum and minimum strain peak of each load cycle, regardless where the zero-line is.

- Determination of the average of all strain differences in each loading cycle, obtaining one single strain value (strain amplitude) for each file. This value is then assigned to the timestamp of the file.

- Use of the time stamp, to obtain the temperature of the pavement from the temperature file and combine it with the strain amplitude in a table.

\section{Experimental results}

\subsection{Field test results, full-size MLS10 loading}

Measurements obtained by the gauges embedded $11 \mathrm{~cm}$ below the surface (TL4 and TQ4) resulted in very low strains. The reason was the extreme rigidity of the pavement especially at low temperatures, where stiffness of asphalt material increases. For this reason, records of these gauges were not considered for the analysis and only strain gauges BQ4 and BL4, at $3 \mathrm{~cm}$ depth, were taken into account. One of the most important variables to take into consideration for the strain analysis is the rolling speed of the MLS10 loads, as well as the pavement temperature. Regarding the speed, all measurements presented here were done for $22 \mathrm{~km} / \mathrm{h}$. As for the temperature, it was observed that the recorded values had usually important fluctuations during a day, partially explained by the expected increase and decrease of air temperature in day time and night time respectively. However, it was also perceived that the temperature rose particularly when the MLS10 was operational. This is due to the heat generated by the MLS10 itself and the heat produced by the energy liberated by the internal friction of the pavement under continuous loading. Further, the temperature profiles in pavements are not homogeneous. Layers close to the surface are reacting faster and more distinctively to changes of the air temperature, whereas towards the bottom, layers tend to respond slower and in a more moderate way to environmental temperature conditions. In order to get a unique representative value, the recorded temperatures of each sensor were averaged and defined as the pavement temperature. During the field performance tests, these temperatures ranged from 6 to $36^{\circ} \mathrm{C}$. Figure 7 presents strain measurements of four MLS10 load applications at pavement temperatures of ca. 20, 25, 30 and $35^{\circ} \mathrm{C}$. Strains recorded in the trafficking direction by sensor BL4 are small and present a minor compressive peak followed by a comparatively larger tensile peak and a subsequent compressive peak. Strains obtained by the sensor perpendicular to the trafficking direction (BQ4) are of pure compressive nature. The effect of the material viscoelasticity results in the asymmetric shape of the strain curves under transient tire loading, specifically due to delayed recovery of the pavement after the tire has passed the sensor position. The strains amplitudes registered by the gauge positioned perpendicular to the trafficking direction (BQ4), grows steadily with increasing temperature. A moderate grow occurs for the strains orientated in the rolling direction (BL4).

The variation of the strain amplitudes obtained during the course of the field tests versus the 
Fig. 7 Examples of strain measurements induced by MLS10 loads at different temperatures in the longitudinal and perpendicular direction
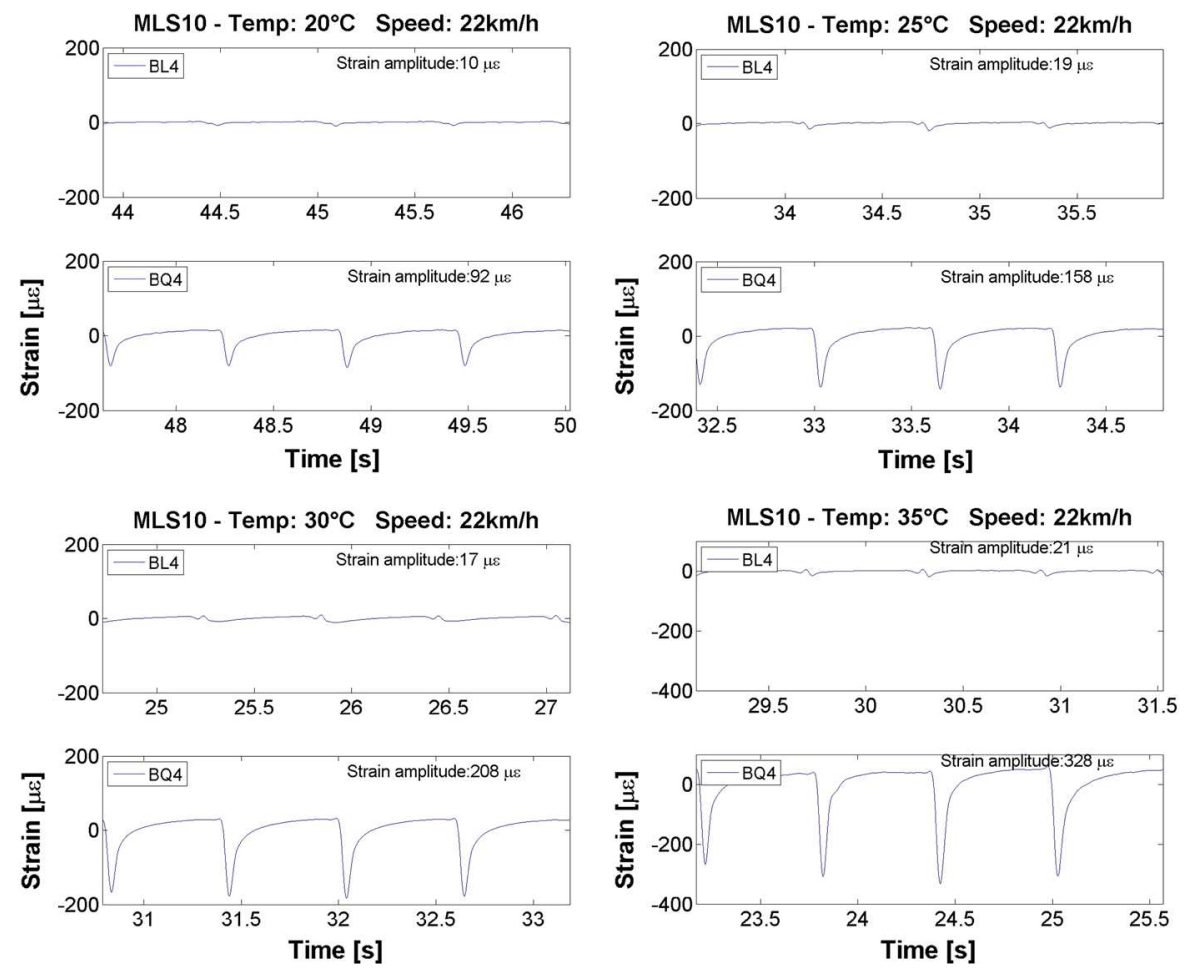

temperature of the pavement is depicted in Fig. 8. The graphs show that the clouds of points have a shape that starts from a certain minimum value in the low temperature range, grows when temperatures increase and reaches a plateau for higher temperatures. A sigmoid function was proposed to model this behavior. The regression variables are also shown in the figure.

\subsection{Laboratory test results, down-scaled MMLS3 loading}

Similarly as in the field tests, in the laboratory, measurements obtained by the gauges embedded $11 \mathrm{~cm}$ below the surface (TL4 and TQ4) resulted in very low strains. Therefore, only gauges BQ4 and BL4 at $3 \mathrm{~cm}$ depth were taken into account. Examples of strains measured by the gauges under the down-scaled load of the MMLS3 are presented in Fig. 9. Each diagram presents measurements carried out considering a combination of the extreme speeds and temperatures. Strains recorded by sensor BL4 (installed along the trafficking direction) present a compressive peak followed by a tensile peak of the same order of magnitude. This pattern was observed for all temperatures and speed combinations. However, previous reports have shown $[8,14,15]$ that horizontal strains measured in the same direction of a rolling tire usually show three alternating peaks. The first and last peaks are of the same nature (either tensile or compressive), whereas the middle peak is of opposite sign. This pattern changes depending on the depth at which the gauge is installed. Typically, if the considered position is on the pavement surface, peaks will alternate between tension, compression and tension. The opposite might occur if the observed position is on the bottom of a layer. One reason why the measurements do not show the expected three peaks, could be due to the fact that the length of the strain gauge $(10 \mathrm{~cm})$ is larger than the length of the footprint of the MMLS3 tire $(8 \mathrm{~cm})$. This might partly level out tensile and compression strains over the length of the strain gauge. Therefore, MMLS3 results in the longitudinal directions are suspected to be a smoothed version of the real strain curve.

Strains obtained by the sensor perpendicular to the trafficking direction (BQ4) are of pure tensile nature. This behavior is opposite to the results obtained in the full-size MLS10 tests. The effect of the material viscoelasticity can be observed again in the asymmetric shape of the strain curves. As expected, strain 
Fig. 8 Sigmoid approximation of MLS10 BL4 (left) and gauge BQ4 (right) strain amplitudes for gauge
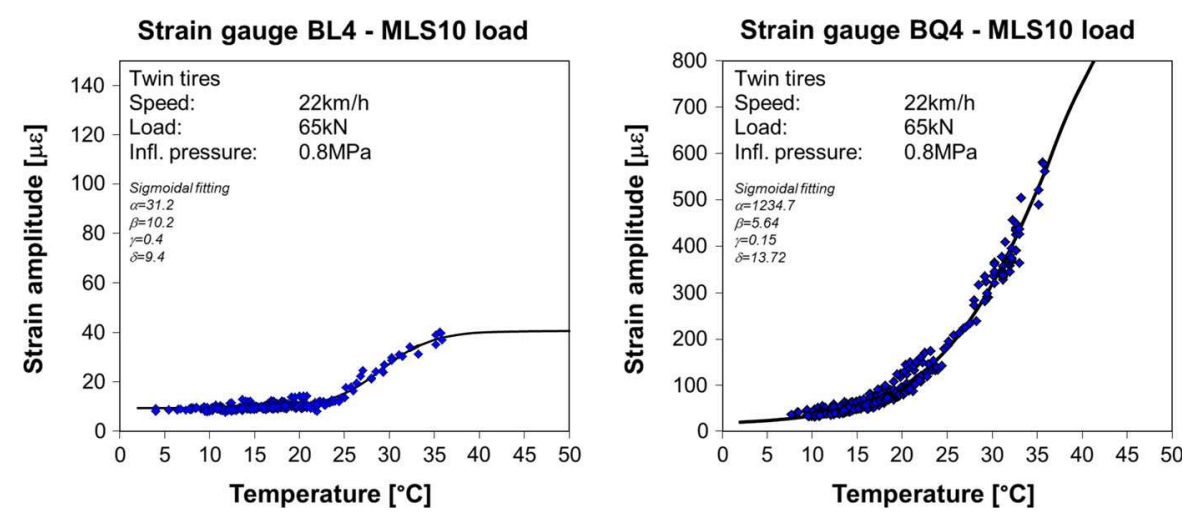

Fig. 9 Examples of MMLS3 induced strains at different temperatures and loading speeds in the longitudinal and perpendicular direction
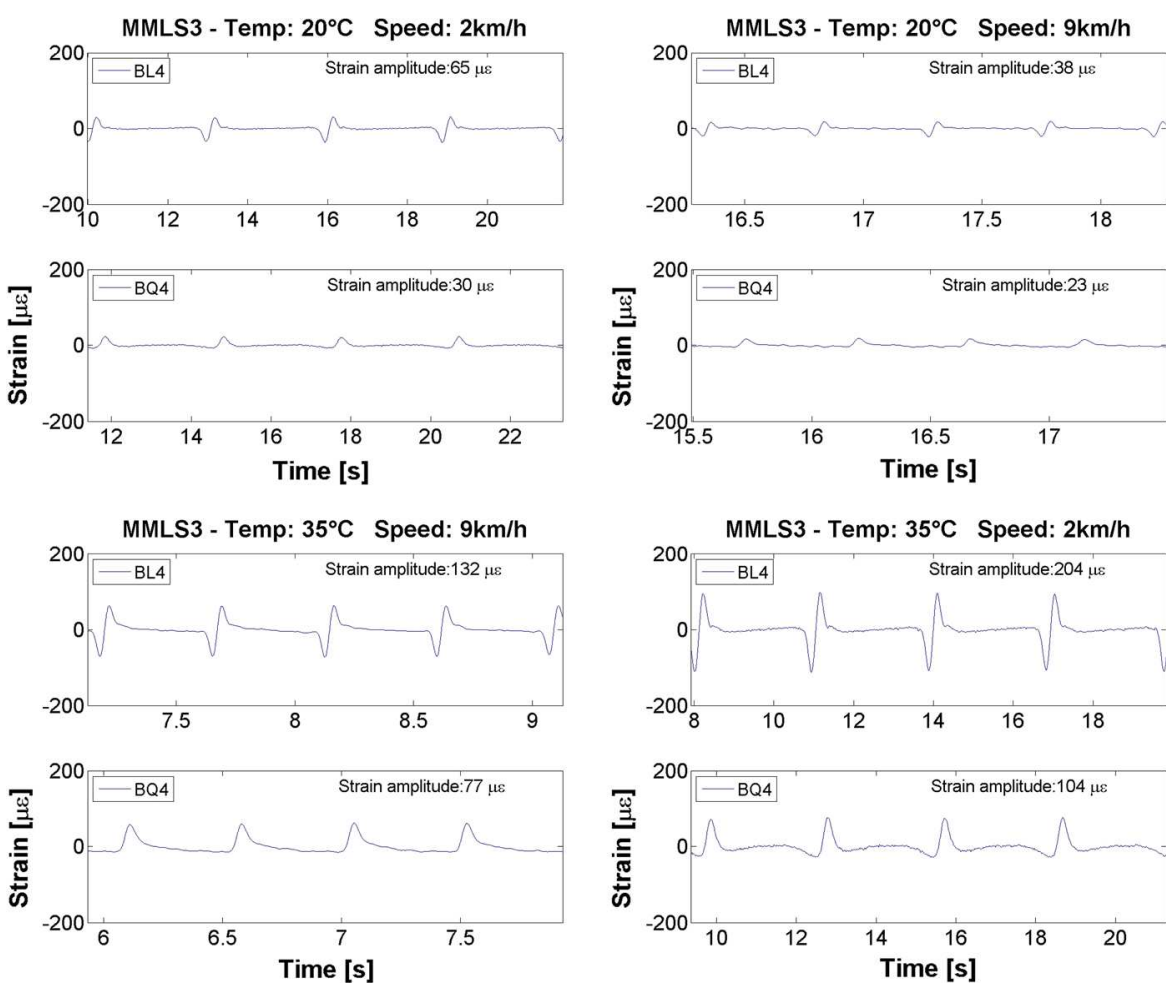

amplitudes grow with the increase of temperature. However, it is interesting to note that strains amplitude values along the trafficking direction (gauge BL4) seem to be more sensitive to temperature changes than strains perpendicular to the trafficking direction (gauge BQ4) then the first ones show a more steadily grow with the increase of temperature than the second ones. The inverse situation was observed in the fullscale field testing. The effect of speed in the strain amplitudes is also clearly visible: for the same load and temperature, higher rolling speeds induce smaller stains.

Figures 10 and 11 present BL4 and BQ4 stain amplitudes obtained for all combination of speeds and temperatures. Each temperature is represented with a different marker. The values grouped by the same temperatures were approximated with potential functions $\mathrm{y}=\mathrm{ax}{ }^{\mathrm{b}}$ and, as a result, expected strain amplitudes for $22 \mathrm{~km} / \mathrm{h}$ were obtained, as presented in Table 3. Sigmoid functions were proposed to model 


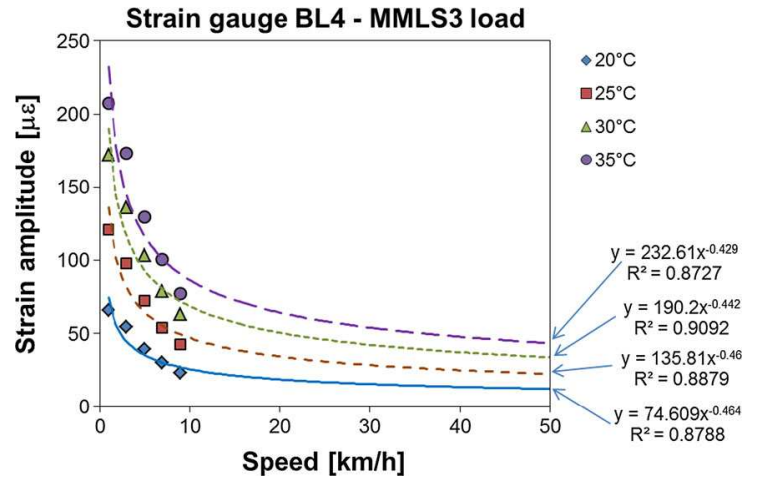

Fig. 10 BL4 strain amplitudes versus MMLS3 speed and potential approximation

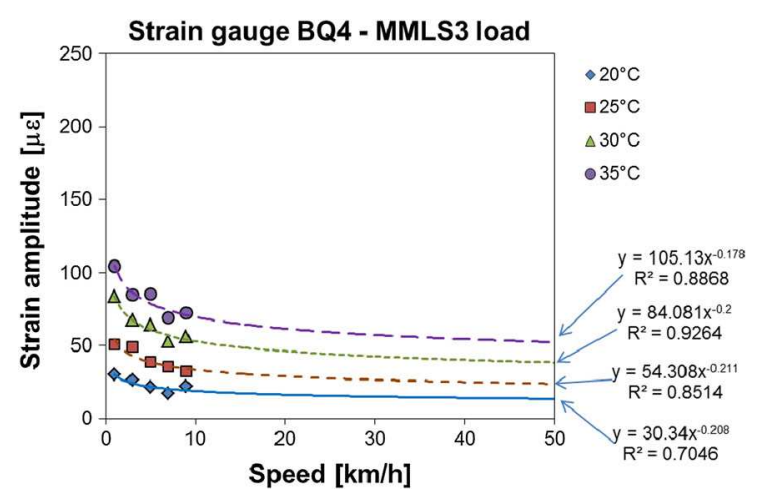

Fig. 11 BQ4 strain amplitudes versus MMLS3 speed and potential approximation

the MMLS3 extrapolated strain amplitudes at $22 \mathrm{~km} / \mathrm{h}$ versus the pavement temperature. The results and parameters are displayed in Fig. 12.

\subsection{Comparison of MLS10 and MMLS3 measured strains}

The strains measured directly under the tires of both, down-scaled and full-size load simulators are different, not only in amplitude but also in shape, sign and duration (Figs. 7 and 9). Gauge BL4 measured longitudinal strains under MLS10 loading, show compression-tension-compression peaks. On the other hand, MMLS3 strains shows only compression-tension peaks, as mentioned before. Further, the peaks induced by the full-size loading are less pronounced than those measured under down-scaled trafficking. Instead, strains perpendicular to MLS10 trafficking direction are purely compressive and peaks
Table 3 Strain amplitudes extrapolation for $22 \mathrm{~km} / \mathrm{h}$

\begin{tabular}{llcll}
\hline Sensor & $\begin{array}{l}\text { Temperature } \\
\left({ }^{\circ} \mathrm{C}\right)\end{array}$ & Coef. a & Coef. b & $\begin{array}{l}\text { Strain } \\
\text { amplitude }(\mu \varepsilon)\end{array}$ \\
\hline BL4 & 20 & 232.61 & -0.429 & 61.8 \\
& 25 & 190.2 & -0.442 & 48.5 \\
& 30 & 135.81 & -0.460 & 32.8 \\
& 35 & 74.61 & -0.464 & 17.8 \\
BQ4 & 20 & 105.13 & -0.178 & 60.6 \\
& 25 & 84.08 & -0.200 & 45.3 \\
& 30 & 54.31 & -0.211 & 28.3 \\
& 35 & 30.34 & -0.208 & 16.0 \\
\hline
\end{tabular}

are highly temperature dependent, whereas MMLS3 strains in the same direction are of tensile nature and present smaller peaks.

The deformation of a pavement as a result of the application of a load on the surface, translates in compressive horizontal strains on top and tensile strains on the bottom of the structural volume affected by the load. The size of the affected volume will depend on the magnitude of the applied load. Compressive perpendicular strains measured under fullsize trafficking indicates that the sensor BQ4 is on the upper side of the neutral axis, where compressive strains are predominant. In the case of down-scaled trafficking, BQ4 is positioned below the neutral axis. Both strain signals show the dependence of the strain values to temperature and, in case of MMLS3 loading, dependence to loading speed was also demonstrated. Figure 13 shows the comparison of the strains amplitudes obtained from the analysis of the sigmoidal curves for both load simulators and in both measuring directions, considering a trafficking speed of $22 \mathrm{~km} / \mathrm{h}$. These diagrams show that, right directly under the tires the down-scaled loading of the MMLS3 induces higher longitudinal strain amplitudes than the dull-size load of the MLS10 simulator. However, the difference in strain amplitudes might be due to the fact that, in the case of the MLS10 loading, strain gauges were located between the full-size twin tires, whereas for the MMLS3 loading, strains were measured under the small single MMLS3 tires. On the other hand, perpendicular to trafficking direction, MLS10 generate larger compressive strains than MMLS3. This difference growths even more at higher temperatures. These results show that, although the load of the MMLS3 is much smaller, the effect in terms of strains 

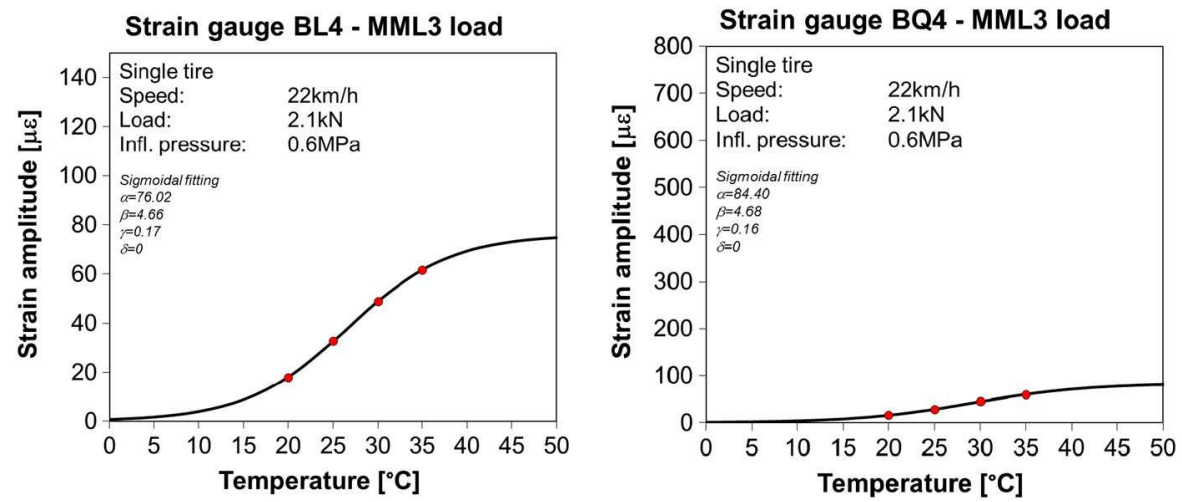

Fig. 12 Sigmoid fitting of MMLS3 strain amplitudes extrapolated to $22 \mathrm{~km} / \mathrm{h}$ for gauge BL4 (left) and gauge BQ4 (right)
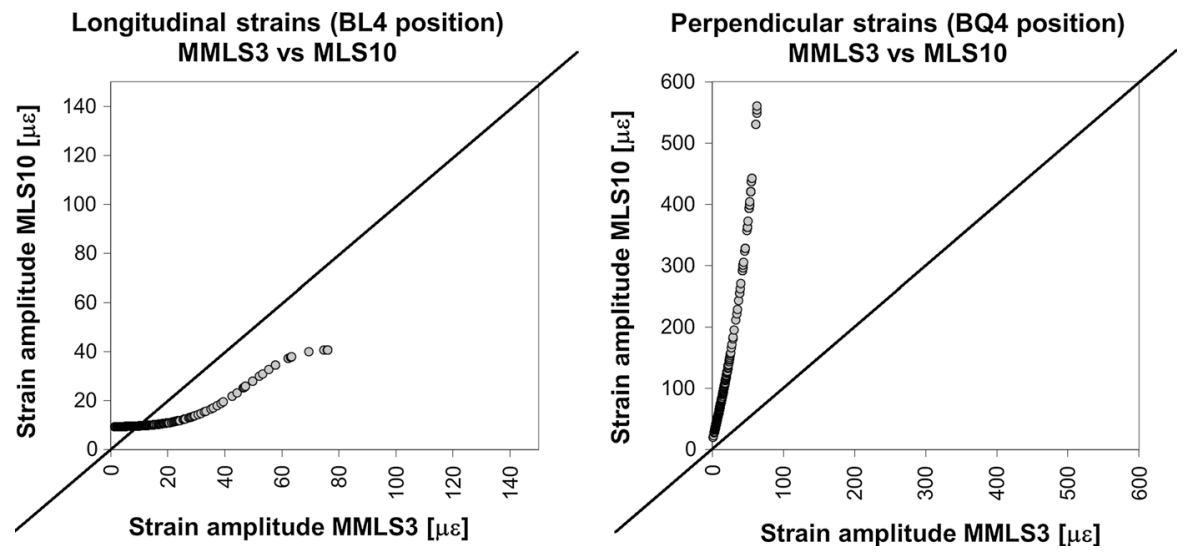

Fig. 13 Comparison of MLS10 versus MMLS3 induced strain amplitudes for the longitudinal (left) and perpendicular (right) to trafficking directions

amplitude near the pavement surface can affect more the pavement than the full-size load of the MLS10. Therefore, the MMLS3 can be used for analyzing the effect of rolling loads on surface layers, even by stiff structures.

\section{Simulation of the pavement response under down-scaled and full-size loading}

\subsection{Finite element model}

In order to perform a theoretical analysis of the stresses and strains obtained during the experimental phase, two different finite element models (FEM) were developed for the MLS10 and MMLS3 configuration using commercial software Abaqus 6.8. With them, selected experimental conditions were simulated as closely as possible aiming at representing the real conditions of load dimensions (footprint), speed, temperature of the structure, materials, etc.

Firstly, a three dimensional model was prepared to simulate the response of the pavement to a single passing of one of the MLS10 twin tires. Then, another model was developed to simulate the passing of one of the reduced scale tires of the MMLS3. For the simulation of MLS10 loading, the semi-infinite geometry of the structure was modeled as a block with a surface area of $2.25 \mathrm{~m}$ length and $2 \mathrm{~m}$ width (Fig. 14). This size was chosen to be as big as possible, in order to avoid the influence of the bounds of the model on the calculations but still allow a reasonable calculation time for solving. The model included the asphalt and stabilization layers with a total thickness of $59 \mathrm{~cm}$. 
Fig. 14 View of the simulations of the full-size (upper panel) and downscaled (lower panel) loading on the pavement
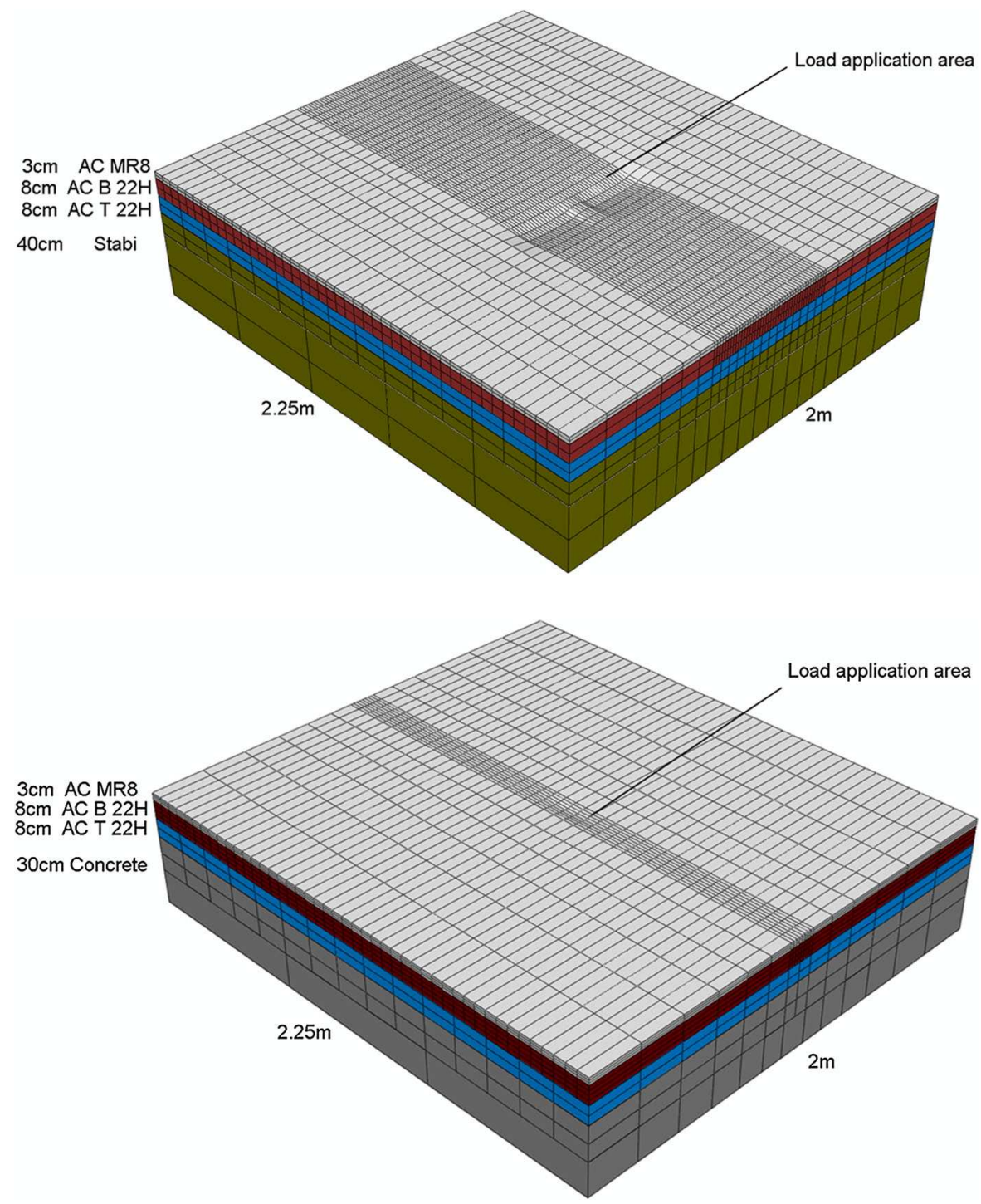

The block modeled for estimating the MMLS3 trafficking response was of the same size as described before, but only comprised the $19 \mathrm{~cm}$ asphalt concrete layers on top of a $30 \mathrm{~cm}$ high cement concrete plate, totalizing a $49 \mathrm{~cm}$ thick block. The mesh was designed with a higher degree of refinement close to the load application area, in order to account for the fast changing strains of the pavement in this area. Temperature dependent linear elastic and viscoelastic material models were used to characterize the asphalt layers. Linear elastic material was assumed to model the cement stabilized layer and the cement concrete plate respectively. Full adhesion between all layers was assumed. The values for the material models (temperature dependent elastic modulus) were obtained from laboratory tests as explained below. The tire loads from both load simulators were modeled as a constant vertical pressure, moving along the load application path. Therefore, for each simulation speed, load and size of the tire footprint were considered. Furthermore, in order to simulate the material response to dynamic loading, inertia was taken into account.

\subsection{Material characterization}

Mechanical material properties of the asphalt layers were determined in the laboratory. Cores from the not- 
Table 4 Input parameters for FEM

\begin{tabular}{|c|c|c|c|c|c|}
\hline \multirow[t]{2}{*}{ Layer } & \multirow{2}{*}{$\begin{array}{l}\text { Density } \\
\left(\mathrm{Mg} / \mathrm{m}^{3}\right)\end{array}$} & \multirow{2}{*}{$\begin{array}{l}\text { Elastic modulus } \\
\left(20^{\circ} \mathrm{C}\right)(\mathrm{MPa}) ; \\
\text { Poisson's ratio }\end{array}$} & \multirow{2}{*}{$\begin{array}{l}\text { WLF parameters } \\
\mathrm{C} 1, \mathrm{C} 2\end{array}$} & \multicolumn{2}{|c|}{ Prony series parameters } \\
\hline & & & & $\mathrm{g}_{1} ; \mathrm{g}_{2} ; \mathrm{g}_{3} ; \mathrm{g}_{4} ; \mathrm{g}_{5}$ & $\tau_{1} ; \tau_{2} ; \tau_{3} ; \tau_{4} ; \tau_{5}$ \\
\hline AC MR 8 & 2.30 & 3,$925 ; 0.35$ & $-26,21.31$ & $\begin{array}{l}0.600 ; 0.132 ; 0.148 \\
\quad 0.118 ; 0.000\end{array}$ & $\begin{array}{r}0.81 ; 13.59 ; 68.89 \\
1285.61 ; 7427.43\end{array}$ \\
\hline AC B $22 \mathrm{H}$ & 2.39 & 7,$971 ; 0.35$ & $-23,107.55$ & $\begin{array}{l}0.540 ; 0.146 ; 0.017 \\
\quad 0.156 ; 0.140\end{array}$ & $\begin{array}{l}0.53 ; 7.36 ; 68.39 ; 68.39 ; \\
1596.99\end{array}$ \\
\hline AC T $22 \mathrm{H}$ & 2.38 & 8,$128 ; 0.35$ & $-93,-484.15$ & $\begin{array}{l}0.508 ; 0.165 ; 0.156 \\
0.000 ; 0.170\end{array}$ & $\begin{array}{l}0.41 ; 6.03 ; 49.71 ; 971.51 \\
\quad 1343.35\end{array}$ \\
\hline Stabi. layer & 2.14 & 3,$900 ; 0.25$ & - & - & - \\
\hline Concrete block & 2.40 & 23,$000 ; 0.25$ & - & - & - \\
\hline
\end{tabular}

trafficked part in the test section were used to prepare cylindrical specimens and the complex stiffness modulus was obtained by conducting the indirect tensile test at different temperatures $(0,5,10$ and $\left.20^{\circ} \mathrm{C}\right)$ and frequencies $(0.1,1,5$ and $10 \mathrm{~Hz})$. Using the William-Landel-Ferry (WLF) equation, master curves of each specimen at a reference temperature of $20{ }^{\circ} \mathrm{C}$ were calculated, according to next equation:

$\log \left(a_{T}\right)=\frac{-C_{1}\left(T-T_{r}\right)}{C_{2}\left(T-T_{r}\right)}$

where $T$ is the temperature, $T_{\mathrm{r}}$ is a reference temperature, $C_{1}$ and $C_{2}$ are fitting coefficients and $a_{T}$ is the shift factor.

From these results, the linear viscoelastic behavior of the material was characterized using the generalized Maxwell model for the shear relaxation modulus $G_{R}(t)$, as defined by the following Prony series:

$G_{R}(t)=G_{0}-G_{0} \sum_{k=1}^{K} g_{k}\left(1-e^{-t / \tau_{k}}\right)$

where $g_{\mathrm{k}}$ and $\tau_{\mathrm{k}}$ are material parameters and the $G_{0}$ is the instantaneous shear modulus. $G_{0}$ can be deducted from elastic modulus obtained from indirect tensile test considering the Poisson ratio. The Fourier transformation of the Prony series, allows calculating the complex shear modulus as explained in [16].

Elastic moduli for the non-asphalt layers were back calculated using FWD determinations. All these material laboratory and field determined values were incorporated to the FEM. In addition, for taking into account inertia effects material density was considered. The input characteristics for the calculation are summarized in Table 4.

\section{Results and analysis}

In this section, a qualitative comparison between the modeled and measured pavement response to the fullsize and down-scaled loading is presented. Figure 15 shows the strain gauges measurements (solid line) and modeled strains (circular marks) of an MMLS3 tire passing at $9 \mathrm{~km} / \mathrm{h}$ at temperatures of 20, 25, 30 and $35{ }^{\circ} \mathrm{C}$. Only one tire passing was simulated. In this figure, a $0.35 \mathrm{~s}$ time window is shown. This time window corresponds approximately to one tire passing. In reality, successive tire loadings don't let the pavement completely recover between passings. This is especially true at high temperatures due to the effect of the viscoelastic delayed recovery of asphalt mixes. Therefore, only for comparison purposes, all strain records were set to zero at the beginning of the time window. The results show that the model can partially reproduce the shape of the measured strains. As for the longitudinal strains, strain gauge BL4 records show that the MMLS3 induces strains with one compression and one tension peak that slowly returns to the value previous to the loading. On the other hand, the FEM simulation presents a compression-tension-compression form, being the first compression peak bigger than the second one due to the viscoelastic material modeling. The comparison also shows that the model tends to underestimate longitudinal strains, being more accurate at lower temperatures. This finding could be due to the fact that the contact pressure of the rolling tire in the longitudinal direction was not accurately represented by the simple uniform contact pressure model. The modeled strains perpendicular to the trafficking direction correlate accurately with the BQ4 measurements, showing a tension peak of an 

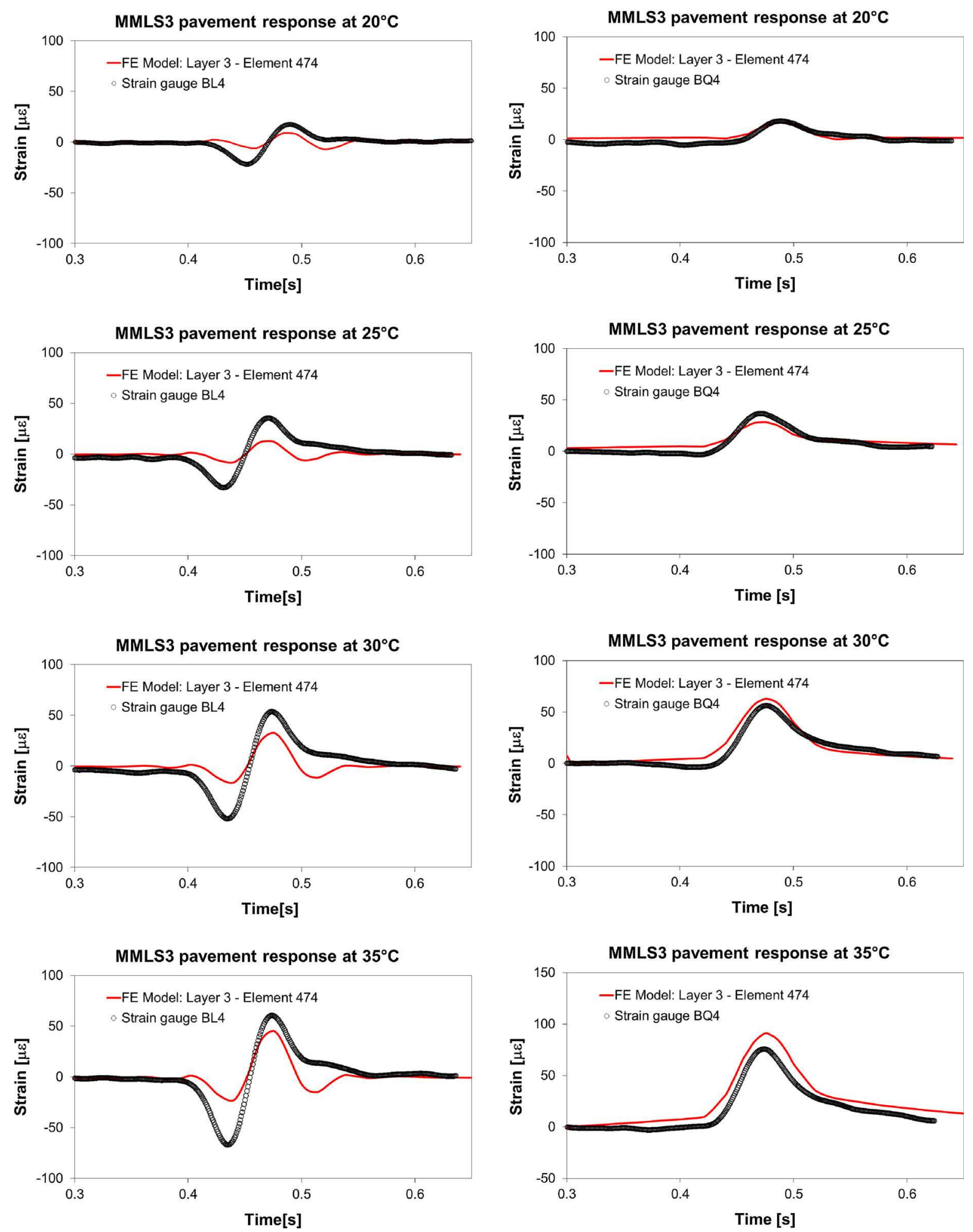

Fig. 15 Comparison of longitudinal (left) and perpendicular (right) strains in $3 \mathrm{~cm}$ depth below the wheel track obtained from the FE model and in situ measurements, for MMLS3 loading 

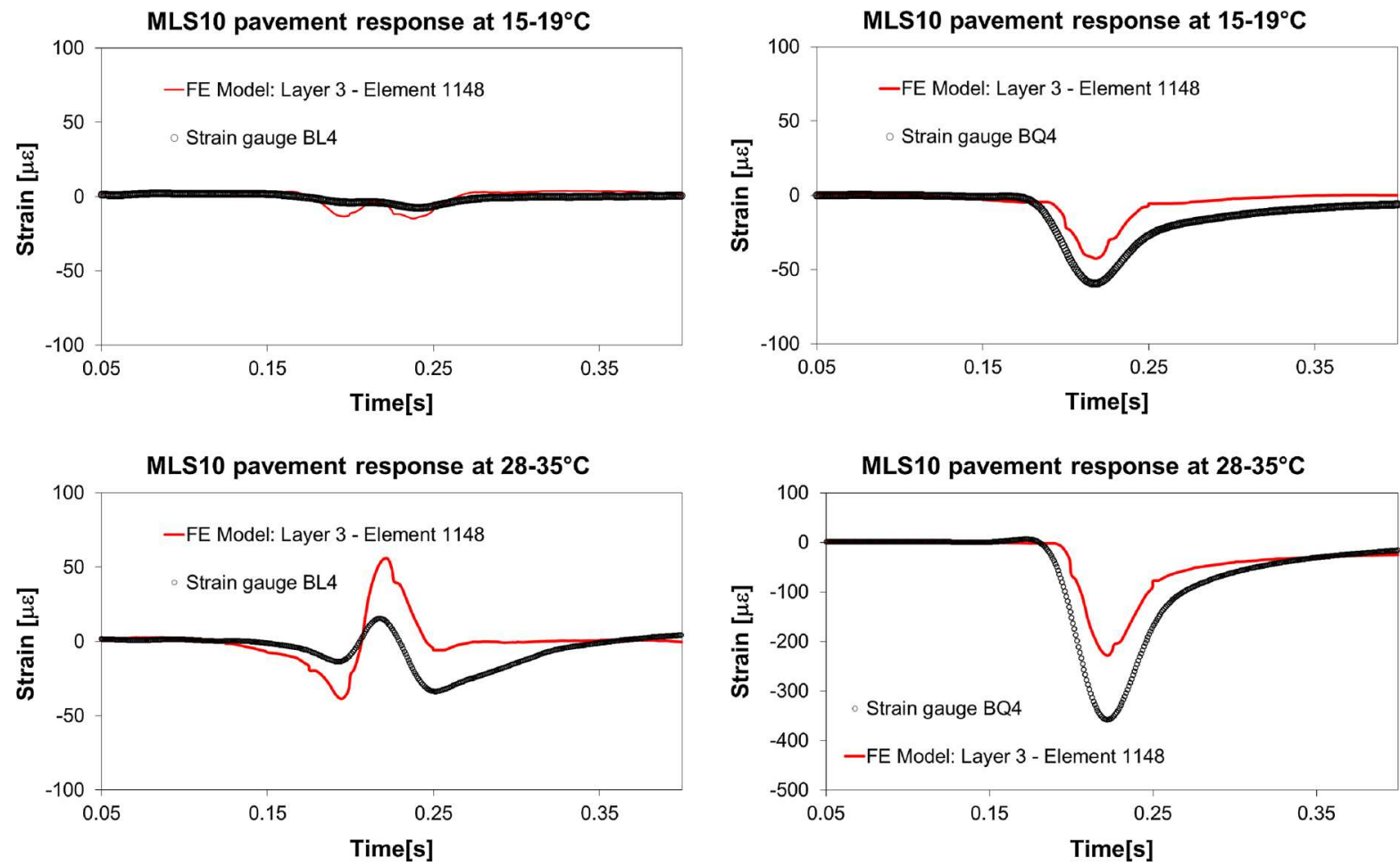

Fig. 16 Comparison of longitudinal (left) and perpendicular (right) strains in $3 \mathrm{~cm}$ depth below the wheel track obtained from the FE model and in situ measurements, for MLS10 loading

asymmetrical shape, due to the viscous nature of the asphalt mixes. In this case, the model tends to overestimate the measured values at higher temperatures.

Figure 16 shows the strain gauges measurements (solid line) and modeled strains (circular marks) of an MLS10 tire passing at $22 \mathrm{~km} / \mathrm{h}$, at a pavement temperature profile ranging from 15 to $19{ }^{\circ} \mathrm{C}$. In the model, every layer was given the measured temperature by each of the thermocouples. As in the case of the MMLS3, the simulation of the MLS10 passing cannot reproduce accurately the measured longitudinal strains BL4. However, both simulation and model show the same shape with three alternating peaks in the negative-positive-negative direction. All the strains are yet in the compression range, having the strain gauge records smaller amplitudes. Stains corresponding to sensor BQ4, placed perpendicular to trafficking direction, are of compressive nature for both measured and simulated response. The effect of viscoelasticity material properties of the asphalt layers can be recognized due to the asymmetric form of the measured curve, which has a clear recovery delay after the tire has passed by. This effect is also partially reproduced by the simulated strains. The model however, is likely to underestimate the strain amplitudes.

Table 5 shows the maximum and minimum extreme strains calculated in each layer and in each direction. These values allow assessing the order of magnitude of the most critical strains induced on the tested slab by the down-scaled and full-size loads. In particular, the table provides theoretical values of the maximum strains in the vertical direction which could not be measured in the test. From Table 5 follows that, for both devices, the highest theoretical compressive negative strains occurs in the top layer and in the vertical direction (MLS10 strains are about twice as high as MMLS3 strains). This means that, because of the stiff support of the asphalt pavement, both the MLS10 and the MMLS3 are affecting the top asphalt pavement layers, i.e. mainly inducing permanent deformation. However, the simulations show that the MLS10 full-scale loading has an effect on all layers, 
Table 5 Maximum and minimum extreme strains $(\mu \varepsilon)$ for different directions due to MLS10 and MMLS3 loading, considering a temperature of $20{ }^{\circ} \mathrm{C}$

\begin{tabular}{|c|c|c|c|c|c|c|}
\hline \multirow[t]{3}{*}{ Layer } & \multicolumn{6}{|c|}{ MLS10 } \\
\hline & \multicolumn{2}{|c|}{ L11 (longitudinal strain) $(\mu \varepsilon)$} & \multicolumn{2}{|c|}{ L22 (vertical strain) $(\mu \varepsilon)$} & \multicolumn{2}{|c|}{ L33 (perpendicular strain) $(\mu \varepsilon)$} \\
\hline & Max & Min & Max & Min & Max & Min \\
\hline MR 8 & 81 & -46 & 32 & -225 & 43 & -56 \\
\hline $\mathrm{AC} \mathrm{B} 22 \mathrm{H}$ & 44 & -29 & 15 & -103 & 27 & -44 \\
\hline \multirow[t]{4}{*}{$\mathrm{AC} \mathrm{T} 22 \mathrm{H}$} & 37 & -19 & 9 & -70 & 20 & -10 \\
\hline & \multicolumn{6}{|c|}{ MMLS3 } \\
\hline & \multicolumn{2}{|c|}{ L11 (longitudinal strain) $(\mu \varepsilon)$} & \multicolumn{2}{|c|}{ L22 (vertical strain) $(\mu \varepsilon)$} & \multicolumn{2}{|c|}{ L33 (perpendicular strain) $(\mu \varepsilon)$} \\
\hline & Max & Min & Max & Min & Max & Min \\
\hline MR 8 & 11 & -16 & 5 & -110 & 22 & -9 \\
\hline $\mathrm{AC} \mathrm{B} 22 \mathrm{H}$ & 6 & -4 & 1 & -32 & 10 & -3 \\
\hline $\mathrm{AC}$ T22H & 2 & -1 & 1 & -7 & 2 & -1 \\
\hline
\end{tabular}

whereas the MMLS3 basically affects the top two layers. In the bottom asphalt layer $\mathrm{AC} \mathrm{T} 22 \mathrm{H}$, the vertical stresses induced by MLS10 are around ten times higher than those of the MMLS3.

On the other hand, the longitudinal and perpendicular strains L11 and L33 in the surface courses are of similar order of magnitude for both loads, downscaled and full-scaled. Nevertheless, it is interesting to note that in the L33 direction (perpendicular to the axis of trafficking) the MMLS3 produces higher maximum tension than compression, though for the MLS10 this strain ranking was opposite. This confirms that both devices produce different loading situations and that scaling down of the structure in terms of thickness should be clearly considered.

\section{Conclusions}

Before drawing a conclusion about the results of this work, it should be pointed out the nature of the strains measured in the pavement under different loadings. In the case of the full-size MLS10 field tests, the recorded strains were obtained between the twin tires. On the other hand, in the MMLS3 laboratory tests, the strains were measured under the small single tires of the small device. Additionally, temperature is also an issue to consider. In the field tests, the pavement was subjected to temperature gradients and fluctuation. In the laboratory, the slab was tested with fixed and homogeneous temperature. In addition, although in both cases the support of the pavement could be considered as highly stiff, the structural support of the asphalt pavement layers in the field and in the lab was not completely similar. The first one had a cement stabilization subgrade while in the laboratory a concrete plate was placed under the asphalt slab. Finally, it is important to consider that the ratio between strain gauge in the longitudinal direction and the length of the small MMLS3 tire footprint might not have been enough large.

The measurements revealed that, for the same pavement, the strains induced by both down-scaled and full-size loads were different, not only in amplitude but also in shape, sign and duration. MMLS3 near surface strain amplitudes recorded in the trafficking direction were found to be larger than strains of the MLS10 in particular for higher temperatures. These results indicate that, although the down-scaled load of MMLS3 is much smaller than the load of the MLS10, it effect in terms of longitudinal strain amplitudes near the pavement surface can affect the pavement than the full-size load. Perpendicular to trafficking direction and directly under the tires, strains generated by the full-size MLS10 were found purely compressive and highly temperature dependent, whereas MMLS3 strains in the same position were of tensile nature.

The FEM models developed for the simulation of the full-size field tests and the down-scale laboratory tests were able to accurately predict the measured strains in most of the cases. These FEM models developed incorporating viscoelastic material 
properties and rolling tires, were used to evaluate the pavement response in terms of strains and under different loading and temperature conditions. They provide a good basis for assessing the scaling effect of the loads and for the theoretical evaluation of the experimental findings. Calculation of the most extreme strains in the pavement indicated that the location of these strains were not at the same position for both traffic loading simulators. The FEM calculations showed that for the stiff pavement studied in these experiments, both devices produce the maximum effect in the vertical direction, i.e. they affect mainly the top layers by inducing high compressive strains. This effect increases even more with higher temperatures and shows that, in terms of resistance against rutting, the structural impact induced by the full-size MLS10 loading is more pronounced than the impact of the down-scaled MMLS3 loading. Furthermore, the MLS10 had a clear effect on all layers whereas the MMLS3 was basically affecting the top layers.

This study confirms that, in order to compare the effect of different loading scales, it is necessary to make a significant analysis of the involved factors as simple scaling down of the stress-strain situation is not easy to achieve. Scaling down should clearly consider scaling down of the pavement structure. Additionally, there is still potential for further refinement of the FEM modeling, e.g. in terms of temperature and contact pressure distribution.

\section{References}

1. AASHO Guide for design of pavement structures (1993) AASHTO, Washington, DC, 1993

2. COST 334 (2001) Effects of wide single tyres and dual tyres. Report, Chapter 4, version 29, November 2001

3. Metcalf JB (1996) NCHRP Synthesis of Highway Practice 235: Application of Full-Scale Accelerated Pavement Testing. TRB, National Research Council, Washington DC 1996

4. Epps A, Ahmed T, Little DC, Mikhail M (2001) Performance Assessment with the MMLS3 at WesTrack. J Assoc Asphalt Paving Technol 70(2001):509-542
5. Walubita LF, Hugo F, Epps A (2000) Performance of rehabilitated lightweight aggregate asphalt concrete pavements under wet and heated model mobile load simulator trafficking: a comparative study with the TxMLS, Report Number 1814-3, Center for Transportation Research at the University of Texas at Austin

6. De Vos ER, Hugo F, Strauss P, Prozzi JA, Fults KW, Tayob H (2007) Comparative scaled MMLS3 tests versus fullscale MLS10 tests in Mozambique 86th Annual Meeting of the Transportation Research Board

7. Kim S, Hugo F, Roesset J (1998) Small-scale accelerated pavement testing. J Transp Eng 124(2):117-122

8. Elseifi M, Al-Qadi I, Yoo P (2006) Viscoelastic modeling and field validation of flexible pavements. J Eng Mech 132(2):172-178

9. Al-Qadi IL, Wang H (2009) Full-depth pavement responses under various tire configurations: accelerated pavement testing and finite element modeling. J Assoc Asphalt Paving Technol 78:645-680 AAPT

10. Kerzreho JP, Hornych P, Chabot A, Deloffre L, Trichet S, Coirier G, Gouy T (2012) Evaluation of the aggressiveness of different multi-axle loads using APT tests proceeding of: 4th International Conference on Accelerated Pavement Testing, Volume: CRC Press 2012, pp 505-517

11. Arraigada M, Partl MN, Pugliessi A (2012) Initial Tests Results from the MLS10 Mobile load simulator in switzerland. advances in pavement design through full-scale accelerated pavement testing-Sep 19-21 2012, Davis, California-Jones, Harvey, Mateos \& Al-Qadi (Eds.), 2012 Taylor \& Francis Group, London, ISBN 978-0-415-621380, pp 277-285

12. Walubita, LF (2000) Accelerated testing of an asphalt pavement with the third-scale model mobile load simulator (MMLS3). Dissertation Stellenbosch: Stellenbosch University

13. VSS (2011) Schweizer Norm (SN) 640324: Dimensionierung Strassenaufbaus, Unterbau und Oberbau. Schweizerischer Verband der Strassen—und Verkehrsfachleute (VSS) VSS-Expertenkommission 5.03

14. Zafir Z, Siddharthan R, Sebaaly PE (1994) Dynamic pavement-strain histories from moving traffic load. J Transp Eng 120(5):821-842

15. Al-Qadi I, Elseifi M, Yoo PJ, Janajreh I (2004) Effect of Wide-Base and Dual Tires Configurations on Pavement Damage. Paper No. 04-4935, 83rd TRB Annual Meetings, 2004

16. Arraigada M, Partl MN, Angelone SM, Martinez F (2009) Evaluation of accelerometers to determine pavement deflections under traffic loads. Mater Struct 42(6):779-790. doi:10.1617/s11527-008-9423-5 